\title{
Influence of Fibre Parameters on Mechanical Properties of Sansevieria Cylindrica Polyester Composites
}

\author{
C. Bennet, N. Rajini, J. T. Winowlin Jappes
}

\begin{abstract}
The sansevieria cylindrica polyester composite slabs are made by compression molding technique using virgin fibres for varying fibre length ( $30 \mathrm{~mm}, 40 \mathrm{~mm}, 50 \mathrm{~mm}$ ) and different weight percentage (20\%wt, 30\%wt, 40\%wt, 50\% wt) under room curing temperature and their mechanical properties have been studied. The inclusion of sansevieria cylindrica fibre as reinforcement into polyester matrix improves the flexural and tensile strength till a certain weight percentage, then it decreases drastically by further addition of fibre. It is observed that the mechanical properties of the composites increase with increase in fibre length from $30 \mathrm{~mm}$ to $40 \mathrm{~mm}$ and there is decrease in their strengths for fibre length of $50 \mathrm{~mm}$.
\end{abstract}

Keywords: Compression molding technique,Curing temperature, Sansevieria Cylindrica fibre

\section{INTRODUCTION}

$\mathrm{N}$ atural fibres have been widely used for preparation of composites for the past few years. Manikandan et al [1] analyzed the tensile and flexural properties of palmyra fibre composites and found that the fibre length and fibre weight percentage as $50 \mathrm{~mm}$ and $53 \%$ respectively for optimum conditions. The mechanical properties of sisal fibre reinforced composites are reported based on fibre length and fibre loading by Joseph et al [2]. Sreenivasan et al [3] studied the influence of fibre parameters on mechanical properties of Sansevieria Cylindrica Fibre composites. The properties of pineapple fibre polyester composites related to fibre loading and fibre length are studied by Uma Devi et al [4] and it is concluded that fibre length of $30 \mathrm{~mm}$ and fibre weight percentage of $30 \%$ wt are optimal for the enhancement of properties. Mechanical properties of banana polyester reinforced composites were studied by Laly.A.Pothan et al[5] with varying fibre length and weight percentage and it was observed that $40 \%$ wt and $30 \mathrm{~mm}$ fibre length showed marginal increase in the strength and water absorption. Udaya Kiran et al [6] studied the tensile properties of natural fibre reinforced polyester composites related to fibre length and weight. Banana fibre reinforced composites mechanical

Revised Manuscript Received on December 29, 2019.

* Correspondence Author

C. Bennet*, Department of Mechancical Engineering, Kalasalingam Academy of Research and Education, Krishnankoil-626126, India. Email: benutha24@rediffmail.com

N. Rajini, Department of Mechancical Engineering, Kalasalingam Academy of Research and Education, Krishnankoil-626126, India. Email: rajiniklu@gmail.com

J. T. Winowlin Jappes, Department of Mechancical Engineering, Kalasalingam Academy of Research and Education, Krishnankoil-626126, India. Email: winowlin@yahoo.com properties were studied by Venkateshwaran et al [7] and the results were reported. Lassaad Ghali et al[8] analyzed the effect of flexural strength on luffa fibre polyester composites related to fibre weight ratio. Tensile properties of banana fibre composites have been studied by Rajesh Ghosh et al [9] with varying fibre volume fraction. Benjamin Lazarus et al [10] have discussed the mechanical properties of sunhemp fibre reinforced polyester matrix to prepare new type of composite materials for potential applications.

Many researchers have analyzed the effect of mechanical properties on varying fibre length of natural fibre composites fabricated under room curing temperature. But studies on the effect of mechanical properties using sansevieria cylindrica fibre composites fabricated under room curing temperature are very limited. Hence an attempt is made to study the same using sansevieria cylindrica fibre reinforced composites.

\section{EXPERIMENTAL}

\section{A. Material USED}

Sansevieria Cylindrca fibres also known as marulkodi or uruvanthandu in local language in the southern part of Tamilnadu are collected from the farms near Cumbum valley and are used as reinforcement. Unsaturated isophthalic polyester (USP) resin supplied by Vasavibala resins, Chennai, India is used as the matrix material. Cobalt Naphthanate is used as an accelerator and Methyl Ethyl Ketone Peroxide (MEKP) is used as catalyst.

\section{B. FABRiCATION of composite}

The sanseveiria cylindrica fibre is cut approximately into optimum fibre length of $40 \mathrm{~mm}$. The unsaturated polyester resin grade VBR 4303 is used as a matrix. Fibres are arranged in random orientation. At first, polyester is mixed with catalyst and accelerator to the required proportion and poured in the mould made of EN90 steel with the dimensions of $180 \times 160 \times 3 \mathrm{~mm}$. After placing the mould in the machine, it is compressed by applying curing pressure of 15 Mpa under room curing temperature.

\section{TESTING OF COMPOSITES}

\section{A. Tensile test}

Universal Testing Machine (Instron series - 3382) is used to do tensile test. ASTM D 3039 standard is followed. $3 \mathrm{~mm}$ thickness is maintained. For each test, five samples are taken and the results are averaged. 


\section{B. Flexural test}

$50 \mathrm{~mm}$ span is taken and $2 \mathrm{~mm} / \mathrm{min}$ of cross head speed is maintained. As per ASTM D 790, flexural tests are performed. For each test, five samples are taken and the results are averaged.

\section{Impact test}

Impact tests are used to measure the resistance to failure of a material when it is subjected to force. Tests are conducted using an impact tester by adopting ASTM D 256. The most common tests of measuring impact energy are Izod Test and Charpy Test.

\section{Scanning Electron Microscope (SEM)}

SEM studies are carried out to find the failure mechanism at the broken surface of the composites. The fibre surface is examined using the instrument Carl zeiss Pvt.Ltd, EVO MA15 model, UK.

\section{RESULT AND DISCUSSIONS}

\section{A. Tensile strength}

The variation of fibre length on tensile properties of sansevieria cylindrica fibre polyester composites is depicted in Figure 1. The maximum tensile strength of $63 \mathrm{MPa}$ is obtained for $40 \mathrm{~mm}$ fibre length. The tensile fractured samples of short sansevieria cylindrica fibre polyester composites are depicted in Figure 2.

The interfacial failure mechanisms observed under tensile loading for $30 \mathrm{~mm}$ and $40 \mathrm{~mm}$ fibre length as shown in Figure 2 (a) and (b). The wetting of short sansevieria cylindrica fibre composites with polyester resin is poor. When tensile load is applied, the fibres are debonded from matrix. Number of fibre ends and defects caused are less for $40 \mathrm{~mm}$ fibre length. Hence a minimum fibre pull out was seen for $40 \mathrm{~mm}$ fibre length. When fibre length is increased to $50 \mathrm{~mm}$, fibre entanglement is found to occur and comparatively larger void size and more fibre pull out occur which pull down the tensile strength. Hence, the critical fibre length is taken as $40 \mathrm{~mm}$.

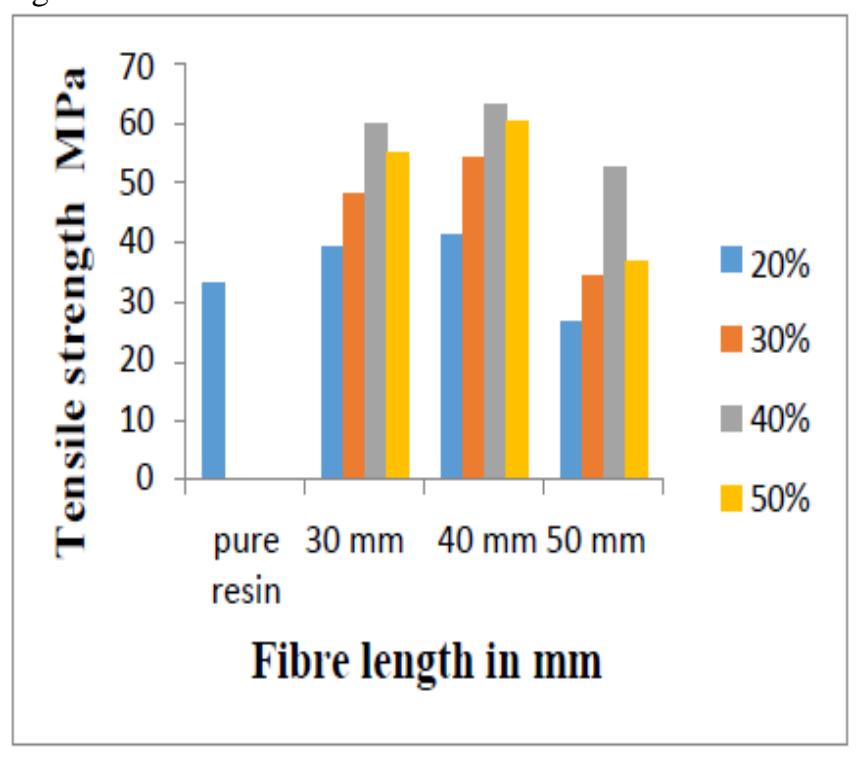

Fig. 1. Effect of fibre length on tensile strength
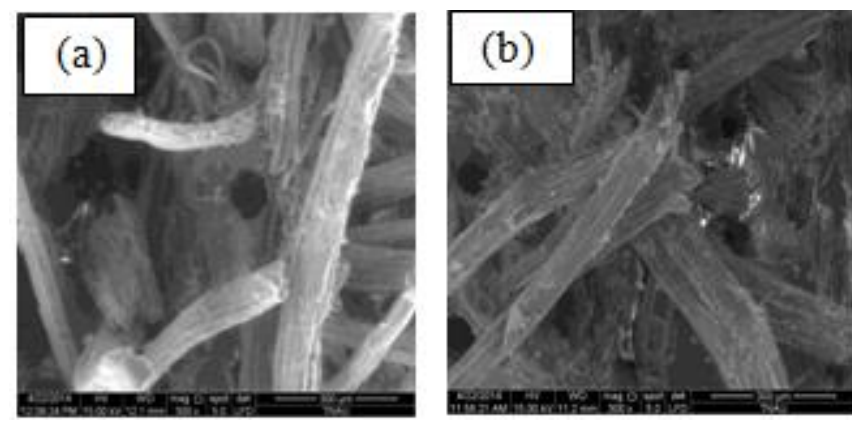

Fig.2. (a) SEM studies (30 mm fibre length) (b) SEM studies (40 $\mathbf{~ m m}$ fibre length)

\section{B. Flexural strength}

The variation of fibre length on flexural properties of sansevieria cylindrica fibre polyester composites is depicted in Figure 3.The flexural strength of $40 \%$ fibre weight percentage of sansevieria cylindrica fibre composites is increased by a factor of 2.23 compared with pure cured resin. The higher flexural strength of $91.57 \mathrm{MPa}$ is obtained for $40 \%$ fibre content. At fibre length above $40 \mathrm{~mm}$, there is a drop in flexural strength for all weight percentages of fibre content when compared to $30 \mathrm{~mm}$ and $40 \mathrm{~mm}$ fibre length respectively. At lower fibre length, more fibre ends are present which could effectively transfer the flexural stress applied over the surface of the composites.Hence, a better strength could be achieved. At a higher fibre length of 50 $\mathrm{mm}$, due to fibre curling and entanglement, stress could not be transferred properly. Hence, a decrease in flexural strength is noticed. The flexural fractograph of short sansevieria cylindrica fibre polyester composites are shown in Figure 1.4.In Figure 1.4(b), for $30 \mathrm{~mm}$ fibre length, more fibre damage could be identified because of poor sustaining capability. But, comparably for fibre length of $40 \mathrm{~mm}$, less damage is caused to the fibre because, the flexural stress build up is low, as it is able to bear the stress by properly distributing among the fibres. It could be inferred from Figure 4(a).

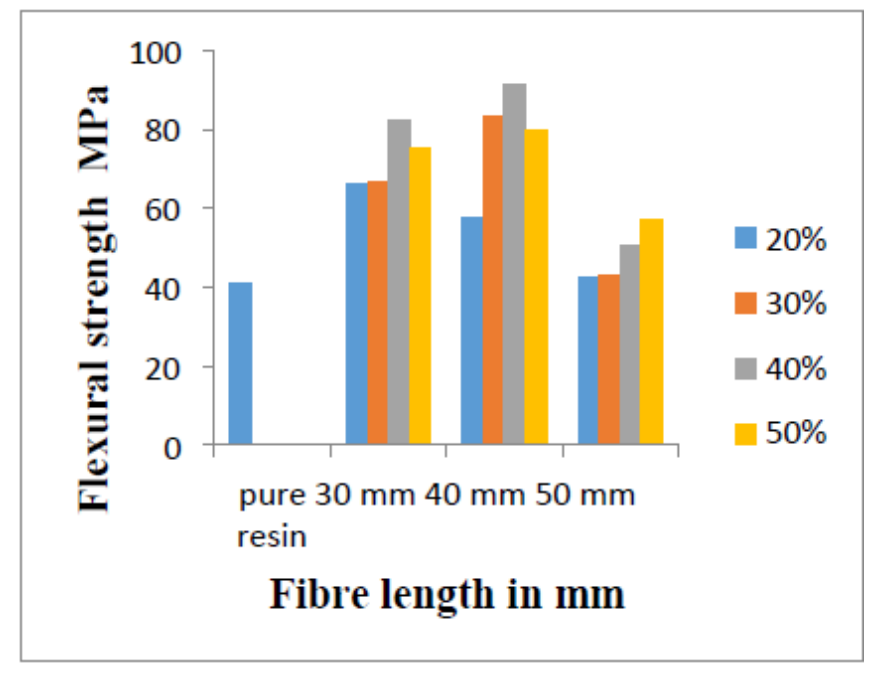

Fig. 3. Effect of fibre length on flexural strength 

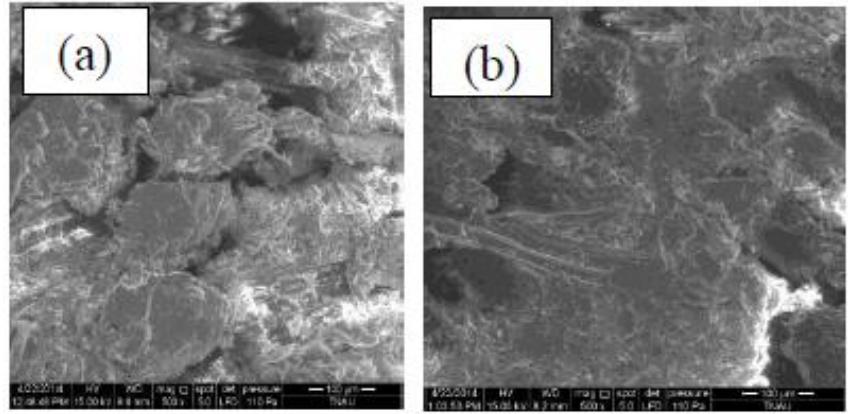

Fig.4. (a) SEM studies (30 $\mathrm{mm}$ fibre length) (b) SEM studies (40 $\mathrm{mm}$ fibre length)

\section{Impact strength}

The effect of fibre length on impact properties of short randomly oriented sansevieria cylindrica fibre polyester composites is shown in Figure 5.Maximum impact strength of $11.123 \mathrm{~J} / \mathrm{cm}^{2}$ is obtained for $40 \mathrm{~mm}$ fibre length. Impact strength of $40 \mathrm{~mm}$ fibre length composites is increased by 22 times compared with pure cured resin. The effect of fibre length influences the energy absorption capability due to the application of sudden load. At lower fibre lengths, more fibre ends are available which reduce the impact strength of the composites. However, beyond a certain limit of fibre length, the agglomeration is found to be higher due to the increasing length of cohesive adhesion among the fibres.

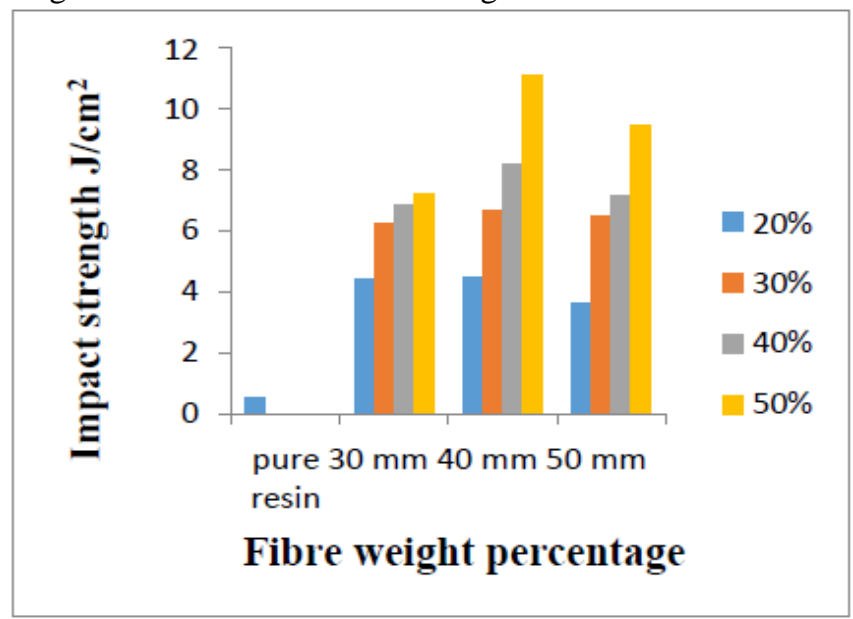

Fig. 5. Effect of fibre length on impact strength

\section{CONCLUSION}

The sansevieria cylindrica polyester composite slabs are made by compression molding technique using virgin fibres for different fibre length and different weight percentage under room curing temperature and their mechanical properties have been studied. It is observed that the tensile, flexural and impact strengths of the composites increase with increase in fibre length from $30 \mathrm{~mm}$ to $40 \mathrm{~mm}$ and then, there is decrease in their strengths for fibre length of $50 \mathrm{~mm}$. The maximum tensile strength and flexural strength of $63 \mathrm{MPa}$ and $91 \mathrm{MPa}$, respectively are obtained for $40 \mathrm{~mm}$ fibre length and $40 \%$ fibre weight. In case of impact strength, the maximum value of $11 \mathrm{~J} / \mathrm{cm}^{2}$ is obtained for $40 \mathrm{~mm}$ fibre length and $50 \%$ fibre weight

\section{ACKNOWLEDGMENT}

The authors express gratitude to the centre for composite materials, Kalasalingam Academy of Research and Education, Krishnankoil for providing necessary help to carry out this work.

\section{REFERENCES}

1. V.Manikandan, R. Velmurugan, SG. Ponnambalam and S.Thomas,'” Mechanical properties of short and unidirectional aligned palmyra fiber reinforced polyester composite, International Journal of plastics Technology", Vol. 8 , 2004, 205-216

2. PV.Joseph, K.Joseph and S.Thomas, ,Effect of processing variables on the mechanical properties of sisal-fiber-reinforced polypropylene composites", Composites Science and Technology, Vol. 59 (11) , 1999 , $1625-1640$

3. VS.Sreenivasan, D.Ravindran, V. Manikandan and R. Narayanasamy, "Mechanical properties of randomly oriented short sansevieria cylindrica fiber/polyester composites", Materials and Design, 2011, 32 (4), 2444-2455

4. L. Uma Devi,SS. Bhagawan and Sabu Thomas, "Mechanical Properties of Pineapple Leaf Fiber-Reinforced Polyester Composites", Journal of Applied Polymer Science, Vol. 64 , 1997, 1739-1748

5. Laly, A. Pothan and Sabu Thomas, "Short banana fiber reinforced polyester composites: mechanical, failure and aging characteristics", Journal of Reinforced Plastics and Composites, , Vol. 16, (8), 1997, 744765

6. Udaya Kiran, C, Ramachandra Reddy, G, Dabade, BM and Rajesham, S , "Tensile properties of sun hemp, banana and sisal fiber reinforced polyester composites, Journal of reinforced plastics and composites", Vol 26 (10), 2007, 1043-1050

7. Venkateshwaran, N, Elayaperumal, A and Jagatheeshwaran, MS , "Effect of fiber length and fiber content on mechanical properties of banana fiber/epoxy composite", Journal of Reinforced Plastics and Composites , Vol. 30 (19), 2010, 1621-1627

8. Lassaad Ghali, Slah Msahli, Mondher Zidi and Faouzi Sakli, "Effects of fiber weight ratio, structure and fiber modification onto flexural properties of luffa-polyester composites", Advances in Materials Physics and Chemistry, Vol. 1, 2011, 78-85

9. Rajesh Ghosh, Reena G and Rama Krishna A, "Effect of fiber volume fraction on the tensile strength of Banana fiber reinforced vinyl ester resin composites", International Journal of Advanced Engineering Sciences and Technologies, Vol. 4 (1) 2011,89-91

10. S.Benjamin Lazarus and V. VelMurugan, "Experimental investigation for mechanical properties of chopped random fiber compression moulded sunnhemp polyester composites", European Journal of Scientific Research, , Vol. 82 (3), 2012, 366-380

\section{AUTHORS PROFILE}

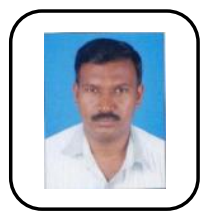

Dr. C. Bennet is an Associate Professor in the Department of Mechanical Engineering, Kalasalingam Academy of Research and Education, Krishnankoil, Tamilnadu, India. His current area of research includes polymer matrix composites, characterization and its studies. He has published a number of papers in journal of national/international repute and presented a number of papers in various conferences/symposia in India and abroad. He is presently guiding a number of master/doctoral research scholars. Dr.C.Bennet is the corresponding author and can be contacted at: benutha24@rediffmail.com

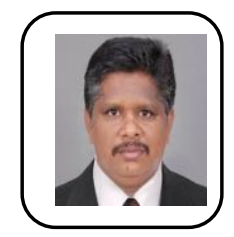

Dr. N. Rajini is a Professor in the Department of Mechanical Engineering, Kalasalingam Academy of Research and Education, Krishnankoil, Tamilnadu, India. His current area of research includes composite materials, tribology studies and bio composites He has published more than 100 numbers of papers in journal of national/international repute and presented a number of papers in various conferences/symposia in India and abroad. He is presently guiding a number of master/doctoral research scholars. 


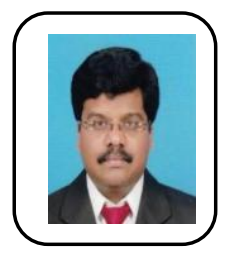

Dr. J. T. Winowlin Jappes is a Senior Professor in the Department of Mechanical Engineering, Kalasalingam Academy of Research and Education, Krishnankoil, Tamilnadu, India. He has more than 18 years of experience in teaching and research. His current area of research includes composite materials, surface coatings and bio composites He has published a number of papers in journal of national/international repute and presented a number of papers in various conferences/symposia in India and abroad. He is presently guiding a number of master/doctoral research scholars. 